\title{
Surface changes in the anaesthetic conjunctiva in man, with special reference to the production of mucus from a non-goblet-cell source
}

\author{
P. N. DILLY ${ }^{1}$ AND I. A. MACKIE ${ }^{2}$ \\ From the 'Department of Anatomy, St George's Hospital Medical School, Cranmer Terrace, \\ London SW17 ORE, and the ${ }^{2}$ Department of Ophthalmology, St George's Hospital, Blackshaw Road, \\ London SW17 OQT
}

SUMmaRY This paper describes changes in the ultrastructure of the human conjunctiva which follows its denervation. The changes are mainly seen in the mucus-producing subsurface vesicles, the surface microvilli, and the intercellular spaces. Some tentative suggestions are made as to how these changes may influence the stability of the tear film in the anaesthetic state.

Although the main concern of the clinician when the eye and its environment are anaesthetic, is the health of the cornea, ophthalmic slit-lamp observations show that the conjunctiva often suffers a change in its characteristics in the denervated state. ${ }^{1}$

In this paper we seek to define these changes in the ultrastructure of the conjunctiva which follow its denervation and relate them to the physiopathology.

Recent studies with scanning and transmission electron microscopy have extended our knowledge of the surface ultrastructure ${ }^{2-7}$ and the goblet cell system of the conjunctiva was described in great detail in an important monograph by Kessing. ${ }^{8}$ It is now appreciated that mucus glycoproteins play an important role in the maintenance of the tear film in the normal eye. ${ }^{9}$ For some time it has been appreciated that the tear film can be unstable in the anaesthetic eye. ${ }^{10}$ It has been suggested that its composition vis-à-vis sialomucins and sulphomucins varies in certain disease states ${ }^{11}$ and that the viscosity is altered by such a change in the composition. The surface of the conjunctival cells that supports this mucus layer has been shown to have microvilli. Investigators have described changes in the surface morphology of these microvilli in abnormal or diseased states of the eye ${ }^{15-7}$ (in dry eyes ${ }^{12}$ ). Previous studies by one of us $^{13}$ suggested that denervation of the cornea and the environmental conjunctiva leads to abnormal epi-

Correspondence to Mr Ian A. Mackie, 99 Harley Street, London WIN IDF. thelial cell turnover. De Haas ${ }^{10}$ suggested that denervation leads to alteration of the epithelial cell surface which in turn leads to an alteration of the adhesive forces between ocular surface and the tear fluid.

Wright and Mackie" demonstrated that between the microvilli of the conjunctiva there is an intravillous layer of mucus histochemically different from the layer of mucus which overlies it and which forms the deepest layer of the tear film. It is possible that physiochemical changes in this region, and abnormal microvilli, could lead to an alteration of the adhesive properties of the mucus and microvilli for each other.

Recent observations ${ }^{2414}$ suggest that besides the lacrimal gland and the goblet cells there is a third source of mucus secretion on to the surface of the conjunctiva. These authors suggest that this source consists of many spherical or oval vesicles 0.3 to $0 \cdot 8$ $\mu \mathrm{m}$ in diameter just below the surface of the outermost layers of cells of the conjunctiva.

\section{Materials and methods}

Biopsy material was obtained from 3 subjects. All had been subjected to alcohol injection of the trigeminal ganglion in the treatment of unilateral chronic paroxysmal trigeminal neuralgia, and had been left with profound sensory loss in the areas of sensory supply of the trigeminal nerve. All 3 eyes showed a mild punctate epithelial keratopathy, but there were no conjunctival signs and there was no evidence of 
external eye infection. Biopsy of conjunctiva from the unaffected side was used as a control. The lower lid on this unaffected side was anaesthetised by an injection of $2 \%$ lignocaine without adrenaline. No anaesthetic was required on the affected side. With a $2 \mathrm{~mm}$ Elliot trephine biopsies were punched out of the exact middle of the palpebral conjunctiva in both lower lids of each patient. A portion of tarsal plate was included to give stability to the biopsy specimen. The punched out biopsies were cut away from the lid substance with a double sharp De Wecker's scissors. Great care was taken to preserve the conjunctival surface of the biopsy, and at no time was the specimen handled with forceps.

The specimens for transmission electron microscope (TEM) histochemistry were fixed in $1 \%$ glutaraldehyde buffered with cacodylate to $\mathrm{pH} 7 \cdot 4$ for 16 hours, postfixed with osmic acid, and stained by a modified Thiery's method. ${ }^{15}$ The experimental specimens and their controls were examined in a Philips 301 TEM.
For scanning electron microscopy (SEM) the specimens were fixed in the same way, but they were then critical-point dried from Freon with carbon dioxide, sputter coated with gold, and examined in a Coates and Welter Quickscan SEM. We also used some pieces of the glutaraldehyde-fixed material for routine histology by light microscopy.

\section{Results}

\section{TRANSMISSION ELECTRON MICROSCOPY Vesicles}

Our observations show the presence of vesicles just below the surface membrane of the conjunctiva in the normal eye similar to those described by Greiner $e t$ al. ${ }^{14}$ (Fig. 1).

The vesicles below the cell membrane are in a region that we found stains heavily with both periodic acid Schiff (PAS) and also with $1 \%$ toluidine blue in light microscope sections. Both stains are known to react with mucopolysaccharides. Transmission

Fig. 1 TEM section of normal conjunctiva, showing the general organisation of the surface layers. Several pale goblet cells are shown, as is the microvillous nature of the border.

Fig. 2 TEM section of an anaesthetic conjunctiva showing a similar region. In this section the packets of mucus in the goblet cells are well stained.

Fig. 3 TEM section of an anaesthetic conjunctiva showing the microvillous border, the layer of subsurface vesicles, and the enlarged intercellular spaces.

Fig. 4 Details of microvilli from the surface of a normal conjunctiva. The hair-like processes extending from their surfaces are well shown.

Fig. 5 Details of microvilli from the surface of an anaesthetic conjunctiva. The surface mucus has stained. The distribution of the stain can be seen to include the 'hairs'.

Fig. 6 Details of the surface of a portion of an anaesthetic conjunctiva. The much increased accumulation of submembrane vesicles is shown, as is a desmosome joining 2 adjacent cells.

Fig. 7 Section of an anaesthetic conjunctiva histochemically stained for mucus. The subsurface vesicle content of mucus and the surface mucus are shown. An arrow indicates a vesicle discharging its content on to the surface. It can be concluded that the 'hairs' on the microvilli are in fact mucus.

Fig. 8 A control histochemical section. This specimen has been treated in exactly the same way as the experimentally treated sections except that the periodic acid and 4TCH tiocarbohydrazide stages were omitted, so that there is no oxidisation of the silver proteinate: firm evidence that it is indeed this histochemical reaction that is localising the mucus.

Fig. 9 A histochemically stained section showing mature mucus-filled vesicles as well as some smaller vesicles that are not so well stained, suggesting a maturation of vesicles. The channels of the endoplasmic reticulum also do not stain.

Fig. 10 Scanning electron micrograph of a small area of normal conjunctiva, showing some clumping of the microvilli with distinct but apparently shorter microvilli on the cell junctions. Field width $44.5 \mu \mathrm{m}$.

Fig. 11 SEM micrograph of the surface of a portion of an anaesthetic conjunctiva showing discrete cells with some clumping of microvilli and apparently raised cell borders. Figs. 10 and 11 together point to some of the difficulties in interpreting changes in surface morphology and correlating them with pathological changes. Without a large sample and a statistical survey such interpretations are fraught with difficulty. Field width $67.6 \mathrm{\mu m}$.

Fig. 12 Section of anaesthetic conjunctiva showing several microvillous patterns and lengths on cells in a small field, suggesting that these differences actually exist within a tiny area, and are not artefact. Field width $22.4 \mu \mathrm{m}$.

Fig. 13 Anaesthetic conjunctiva. A sunken cell surface with short microvilli suggesting that a cell has been shed from this region to reveal an immature cell beneath. Field width $30 \mu \mathrm{m}$.

Fig. 14 A group of white blood cells on the surface of an anaesthetic conjunctiva. They occur more frequently here than in the normal. Field width $34 \cdot 2 \mu \mathrm{m}$.

Fig. 15 The opening of goblet cells with a strand of mucus on the surface of an anaesthetic conjunctiva. It is of note that in this micrograph the cell junctions are marked by a relative absence of microvilli. Field width $30 \mu \mathrm{m}$.

Abbreviations. d, desmosomes; er, endoplasmic reticulum; g, goblet cell; $\mathrm{h}$, hair-like process; i, intercellular space; $\mathrm{j}$, junction between cells; $\mathrm{m}$, mucus; $\mathrm{mv}$, microvillus; $\mathrm{n}$, nucleus; $\mathrm{r}$, ribosomes; $\mathrm{s}$, surface of the conjunctiva; $\mathrm{ss}$, sunken surface of a cell; su, sea-urchin-like clumps of microvilli; v, subsurface vesicle; $w$, white blood corpuscle. 


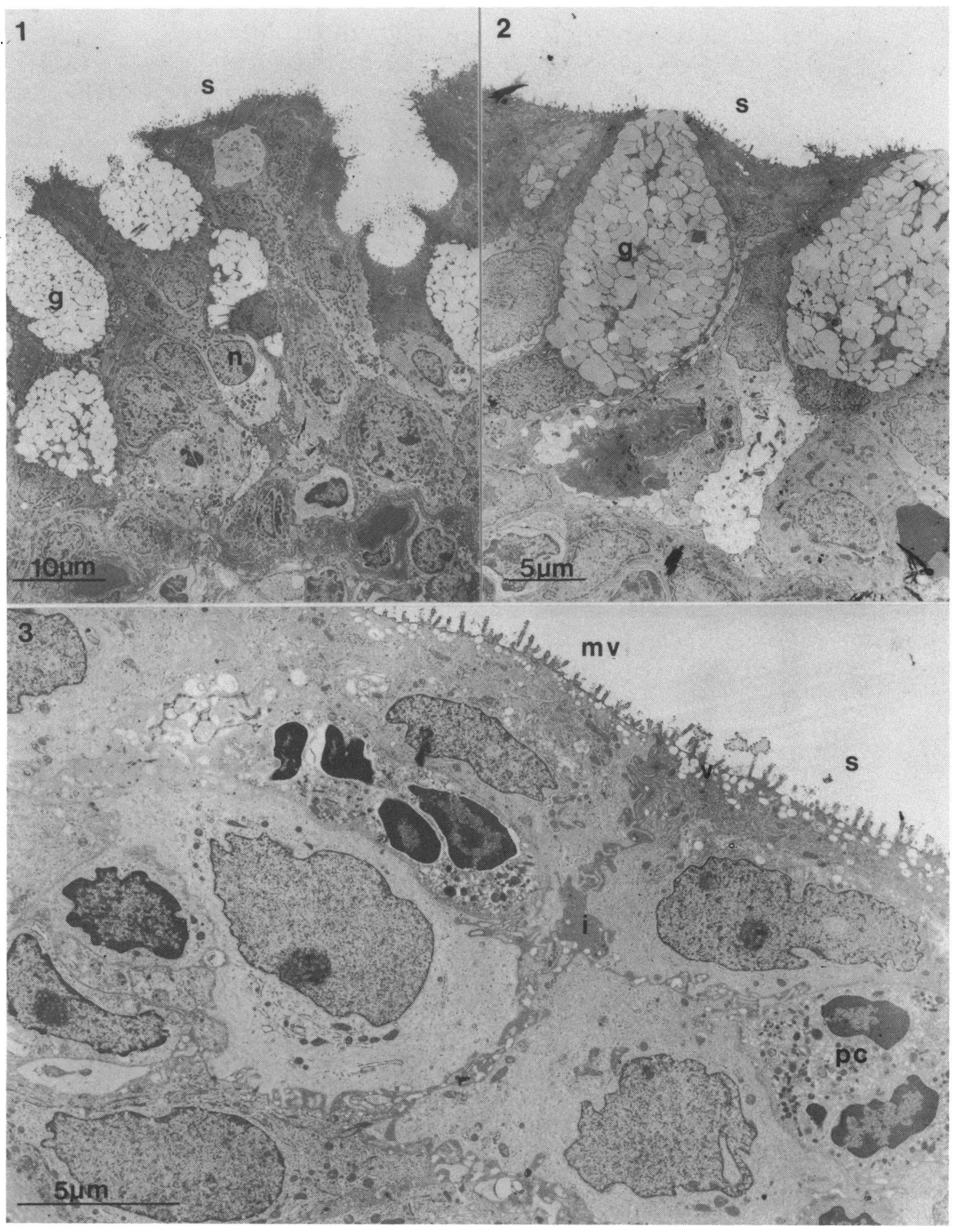




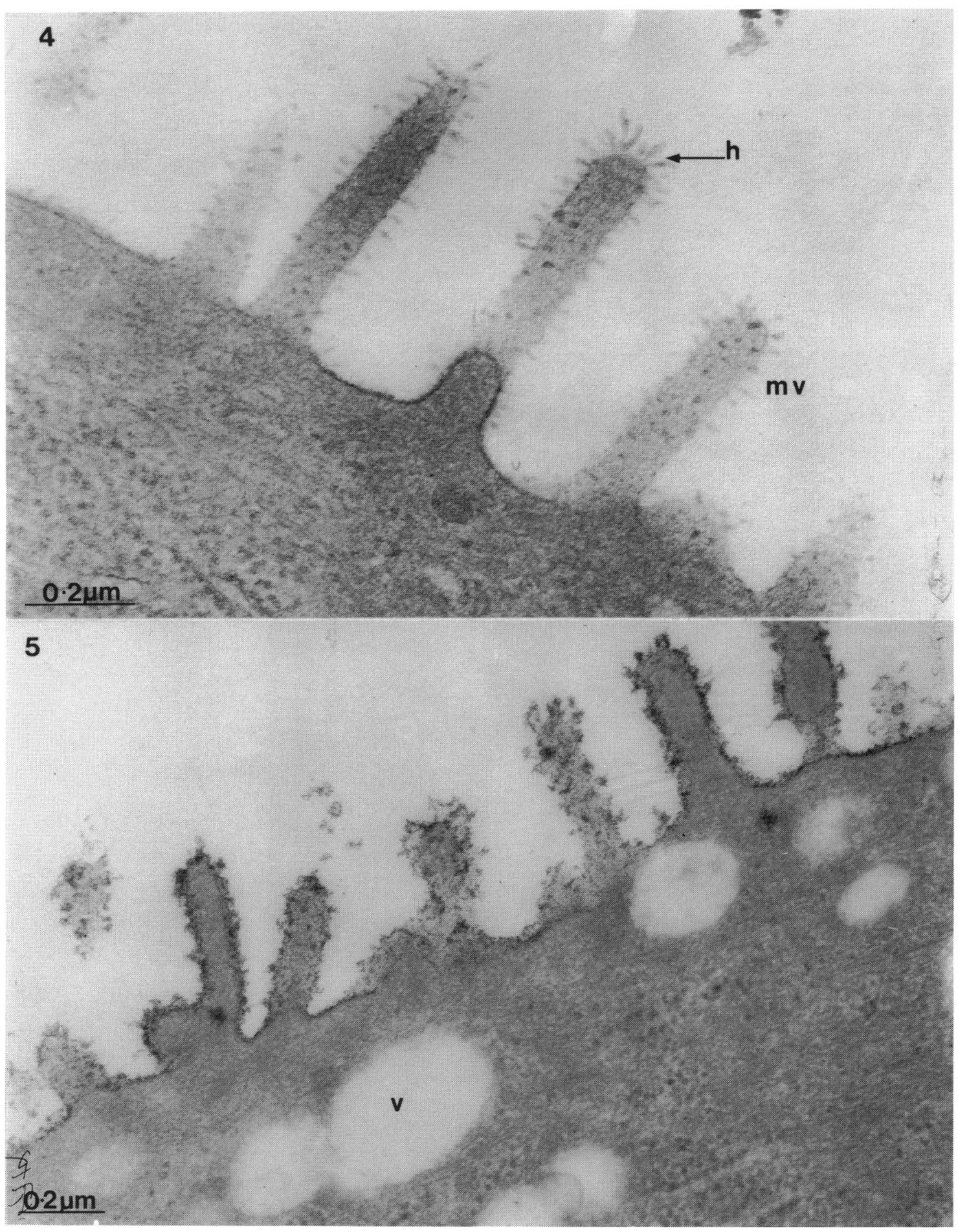




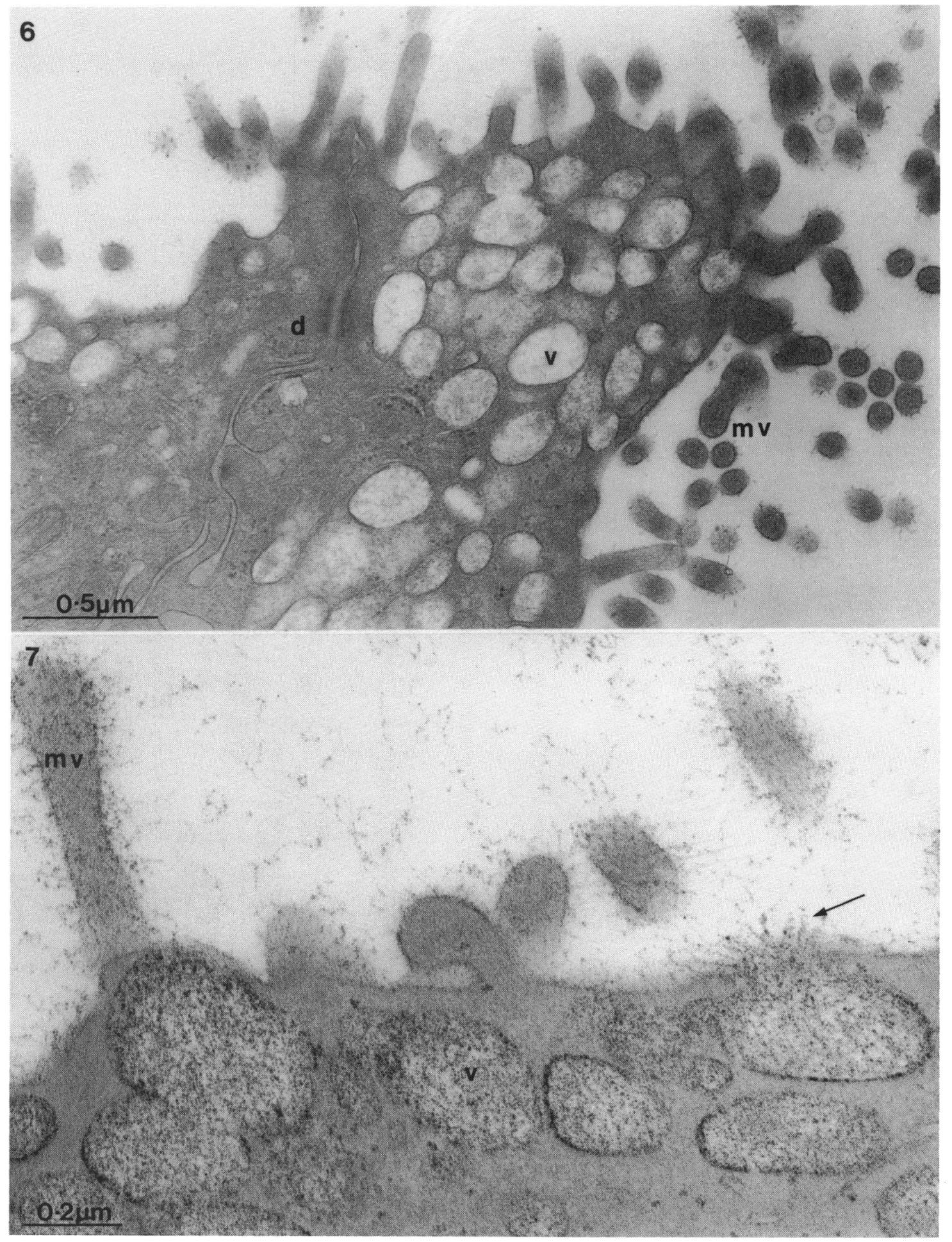




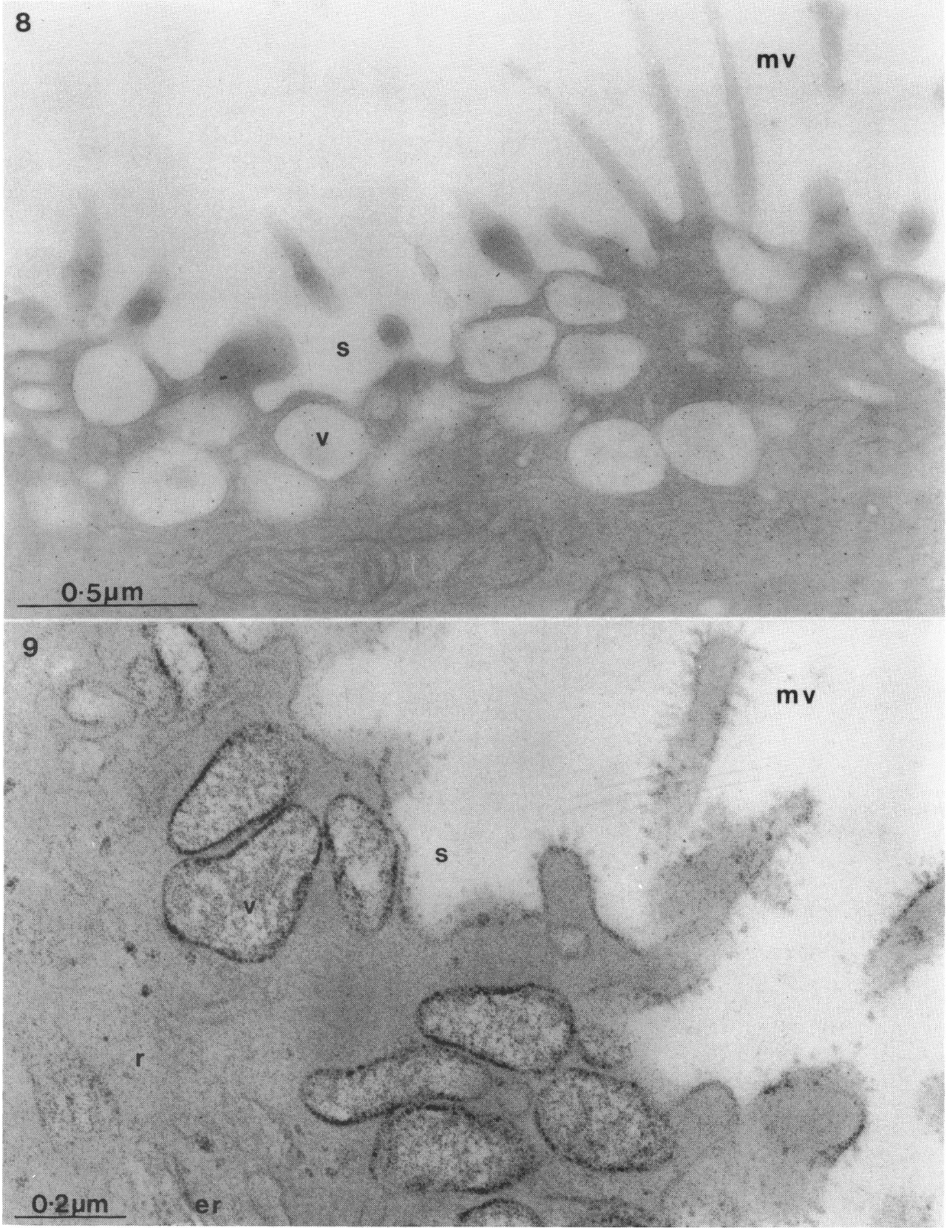




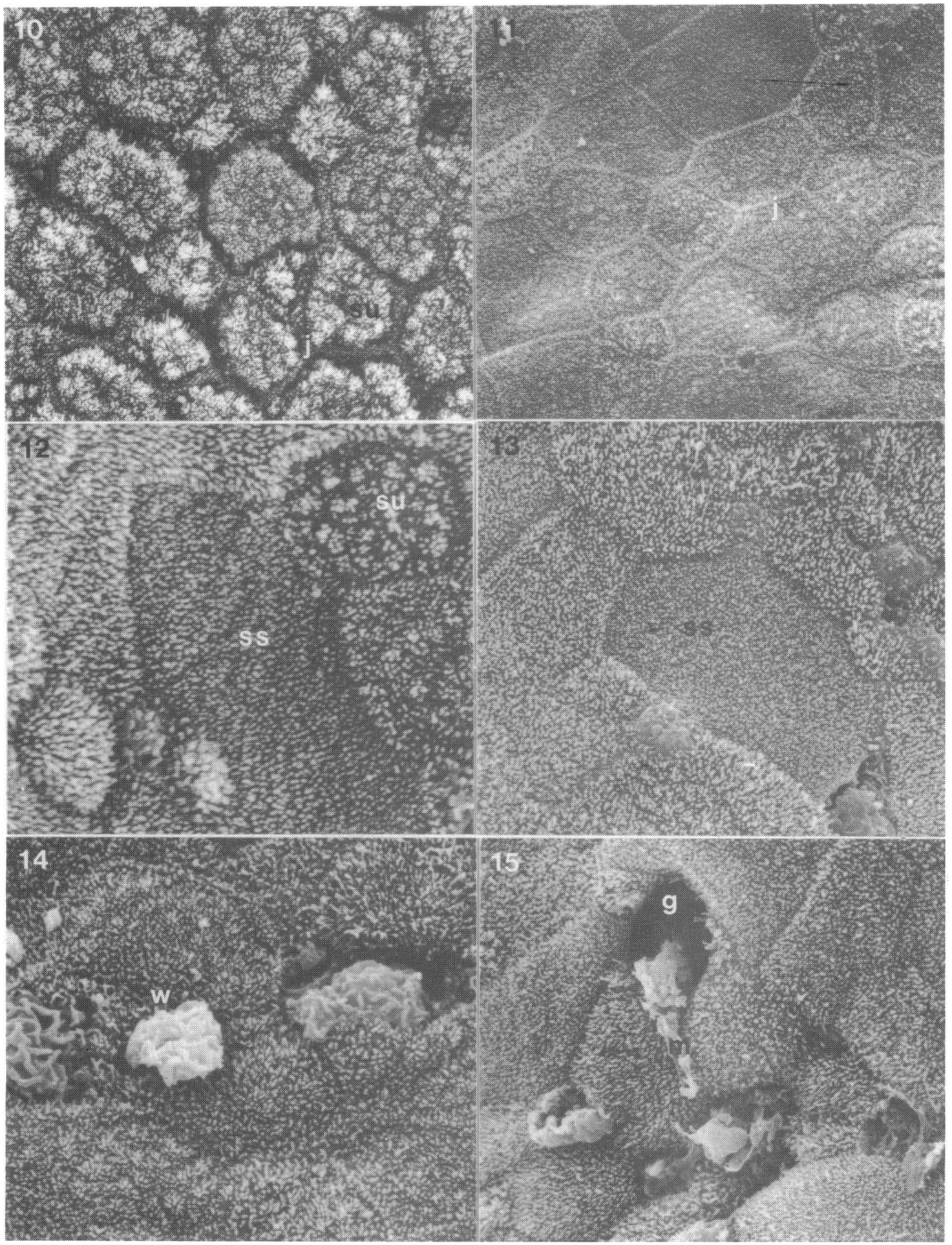


electron microscopy of this area that stains metachromatically with toluidine blue, and is positive with PAS, shows that it contains vesicles. This suggests a mucoprotein content in this area. We have found that vesicles are about 0.3 to $1 \mu \mathrm{m}$ in diameter. They are usually spherical or slightly oval. The content of the vesicles varies from homogeneous pale to fibrillar networked, and there are most stages in between. The vesicles are membrane bound. Sometimes it is possible to find vesicles fused with the surface membrane in a manner suggesting that they are releasing their contents on to the surface of the conjunctiva (Fig. 7).

Histochemical staining of the vesicles reveals that both the vesicle membrane and its contents react to the stain. The membranes of the cells and the mitochondria do not. The other major cell organelles that stain are the ribosomal particles (Figs. 5, 7, 9). Interestingly the vesicles and their contents stain differently from the contents of the goblet cells, suggesting that there are differences between the mucus from these 2 sources, just as there are differences between the intervillous and the supravillous mucus as described by Wright and Mackie. ${ }^{11}$ The amount of stained content of the vesicles varies considerably from pale and apparently empty to quite dense (Figs. 5, 7, 9). The nature of the deposited silver is particulate (Figs. 7,9), and it is reasonable to suppose that the vesicles containing the greatest concentration of particles are the most mature. We have found similar vesicles present in the same region in the anaesthetic eye conjunctiva (Figs. 2, 3, 5, 6). Although we have not undertaken a statistical analysis, we are of the opinion that there are many more vesicles present in this region of the anaesthetic eye than in the normal.

\section{Microvilli}

Electron microscopical histochemical studies show microvilli with membrane or hair-like protrusions from their surface (Fig. 4). We suggest that there is a surface layer of reaction products as well as an accumulation of similar reaction products within the subsurface membrane vesicles. The surface layer of reaction products frequently picks out these protrusions from the microvilli, suggesting that they are part of the surface mucus. The reaction products are also found as hair-like wisps extending between and out from the microvilli (Figs. 5, 7, 9). It is difficult to escape the conclusion that the contents of the subsurface vesicles are distributed throughout the surface glycocalyx (Fig. 7). The distribution of the stain is such as to suggest that the surface of the microvilli as well as the intravillous cell surface is covered by the secretion of the subsurface vesicles. Indeed in some histochemically stained preparations it is possible to trace the reaction products from the vesicle on to the surface region of the conjunctiva. The subsurface vesicles when stained by Thiéry's method do not stain always to the same intensity as the surface layer (Fig. 5). It may be that there are subtle differences between the mucus in the vesicles and the intervillous mucus or that the intervillous mucus is somehow concentrated or changed after it has been secreted.

We found few_if any remarkable differences between the transmission electron microscope appearances of microvilli in the normal and the anaesthetic conjunctiva.

\section{Intercellular spaces}

A frequent finding in the surface layer of cells of the anaesthetic conjunctiva that is not seen in the normal eye is that the intercellular spaces are widely dilated and filled with homogeneous material (Fig. 3). The desmosomes of these cells are still intact, suggesting that this is probably not an artefact. Further evidence against an artefactual explanation for these distended channels is that normal conjunctival biopsy material processed identically and simultaneously does not show these channels. The nature of the contents of these spaces is unknown, but it is tempting to speculate that they represent a source of extracellular secretion or absorption fluid.

\section{SCANNING ELECTRON MICROSCOPY}

The SEM suggests too that, while it is possible to detect differences of clumping and other appearances, as described by Mackie, ${ }^{13}$ these changes depend to a great deal on sample selection and probably represent only degrees of change rather than major pathologically induced differences (Figs. 10,11). There is no doubt, however, that there are more 'sea-urchin'like appearances in the anaesthetic eye than in the normal eye of the same subject.

Besides the sea-urchin-like clumping, the junctions between the cells may be either raised or sunken (Figs. 10,11), both occurring alongside each other in both the normal and anaesthetic conjunctiva.

Both tissues have light and dark cells (Fig. 12), presumably a measure of electron absorption, but perhaps indicating significant physicochemical differences between them. Worthy of note are groups of cells occurring throughout the conjunctiva whose appearance is markedly different from that of the majority of cells. They frequently appear sunken when compared with the surrounding cells, and often their microvilli are shorter (Figs. 12, 13). These sunken cells create the impression that cells that were external to them have sloughed off and been lost, and the surface of these cells represents an immature phase in maturation of surface conjunctival cells. Such cells occur in more or less equivalent numbers in 
both the normal and anaesthetic conjunctivae, and probably represent a normal physiological state of the conjunctiva. It is of interest that there is a noticeable increase in the number of polymorphonuclear leucocytes and probably also of lymphocytes associated with the surface of the anaesthetic conjunctiva, possibly associated with the increased mucus secretion (Fig. 14).

\section{Goblet cells}

There are goblet cells in both the normal and anaesthetic conjunctiva. Their transmission electron microscope appearances are very variable. They all have package-like contents that may be either pale or electron dense. The packages are usually sausage shaped, and their contents are usually heterogeneous. Often the stained densities are arranged in rows. The whole range of package sizes and staining can be found in both the normal and the anaesthetic conjunctivae. Some idea of the extremes of the range are shown (Figs. 1,2). The goblet cells do not stain with our modification of Thiéry's ${ }^{15}$ method. This is true of both the anaesthetic and normal conjunctiva, although an occasional membrane surrounding a packet in the anaesthetic conjunctiva may show patchy light staining. Our preparative technique for scanning electron microscopy deliberately removed most of the mucus from the surface, but occasional strands of mucus can be seen emerging from goblet cells (Fig. 15).

\section{Light and dark cells}

It is possible to classify the cells seen in both transmission and scanning micrographs of the normal and anaesthetic conjunctiva as either light or dark cells, using as a basis for this classification the electron density of the cell or its surface. Closer study shows that there is in fact a gradation of cell densities, and it is really the pale cells that are noticeably different from the remainder. Apart from their difference in electron density, the nature of which it is difficult to determine, there seem to be no easily detectable differences between the cell types. We do not know if the pale cells in TEM sections would appear pale in the scanning microscope, when their surfaces only would be seen. Similar proportions of these cell types occur in both the normal and anaesthetic conjunctiva.

\section{Discussion}

The conclusive test for the contents of the subsurface vesicles is histochemical localisation and identification of their contents at the electron microscope level. The microvillar surface also reacts positively to the same histochemical reaction with silver proteinate, suggesting that the vesicle contents do indeed end up on the conjunctival surface. This material that is found attached to microvilli is usually identified as surface glycoproteins. Our histochemical observations suggest that the mucoprotein of the surface layer is heavily glycosylated, probably more so than that of the surface membrane itself. It is, however, sometimes quite difficult to distinguish between the cell membrane and the layer of glycoprotein intimately associated with its outer surface, perhaps suggesting an intimate contact between them.

We have identified the content of the vesicles of the conjunctival epithelium as containing mucus. It is becoming clear from the accumulating evidence ${ }^{414}$ that the number of these vesicles increases in some eye diseases in association with increased mucus production. This increase is usually marked after sensory denervation of the conjunctiva. " An increase in mucus production in this condition was observed a long time ago. Tagawa ${ }^{16}$ reported that the tear fluid contained a 'copious fatty admixture.' The subsurface vesicle content of the conjunctival cells is well known. Takakusaki $^{2}$ suspected early on that they contained mucus. Srinivasan et al. ${ }^{4}$ reported that the vesicles stained with colloidal iron but not with acid phosphatase, and concluded that the vesicles contained mucopolysaccharides, and that they were not lysosomes. Greiner et al. ${ }^{14}$ on the basis of light microscope observations of metachromasia to toluidine blue and positive PAS reactions came to the conclusion that these vesicles contain a type of mucus. We suggest that excess mucus seen in some eye diseases and especially in the denervated eye originates in the subsurface vesicles.

Another difference between the anaesthetic and normal conjunctiva is the presence of dilated lateral intercellular spaces. Similar widely dilated lateral intercellular spaces have been reported between the epithelial cells of solute transporting organs such as the gall bladder. Studies of the membranes have revealed that the membranes are widely dilated during isotonic water transport but occluded when fluid transport is inhibited. ${ }^{1718}$ These results have been interpreted as evidence for the existence of an epithelial compartment in which the coupling between solute and solvents takes place, and have given rise to suggested mechanisms for transepithelial transport of solutes and water. ${ }^{19-21}$ Fredericksen and Rostgaard $^{22}$ and Rostgaard and Frederiksen ${ }^{23}$ have challenged these results, suggesting that the lateral intercellular spaces were a result of cell shrinkage during preparation for electron microscopy. In our specimens, in which the normal and anaesthetic conjunctival biopsies were processed simultaneously, the existence of lateral intercellular spaces in the anaesthetic conjunctiva suggests some difference between the cells of the 2 types of conjunctivae, even 
if it is only a differential resistance to shrinkage during preparation for electron microscopy. If the spaces are not an artefact, then they suggest that there is a more active fluid transport in the anaesthetic conjunctiva than in the normal.

The patterns adopted by the surface microvilli of the conjunctiva are quite varied. It is probable that they result from the same populations of microvilli being attracted towards one another by differing surface-active and surface-adhesive materials. These materials are the secretion products of the glands of the eye. The eye mucus is secreted from several sources, and each source probably contributes variable amounts to the eye surface mucus. If this is so, then the different portions of the appearances of the microvilli might be thought to represent different physicochemical properties of the mixture of secretions, causing differing adhesiveness between the microvilli. Clumping seems to be restricted to individual cells and does not occur between adjacent cells. Cells with clumped microvilli can occur alongside cells with a more homogeneous distribution of microvilli. These observations would suggest that the microvilli are influenced by the secretions of the cell that bears them and that there is little circulation of the secretion. While we do not know if the clumping does occur in vivo, it is still possible to speculate that it represents a difference in adhesiveness of the secretions between cells, perhaps exaggerated and revealed during the preparation for microscopy.

We are grateful to Miss C. E. Cope for her technical expertise and enthusiasm in support of this study and to Miss M. Stock for secretarial assistance.

\section{References}

1 Mackie IA. Neuroparalytic (neurotrophic) keratitis. In: Transactions of the New Orleans Academy of Ophthalmology. St Louis: Mosby, 1972; 125-42.

2 Takakusaki I. Fine structure of the human palpebral conjunctiva with special reference to the pathological changes in vernal conjunctivitis. Arch Histol Jpn 1969; 30: 247-82.

3 Pfister RR. The normal surface of conjunctiva epithelium. A scanning electron microscope study. Invest Ophthalmol Visual Sci $1975 ; 14: 267-79$.

4 Srinivasan BD, Worgul BV, Iwamoto T, Merriam GR. The conjunctival epithelium. Histochemical and ultrastructural studies on human and rat conjunctiva. Ophthalmic Res 1977; 9: 65-79.

5 Greiner JV, Covington HI, Allansmith MR. Surface morphology of the human upper tarsal conjunctiva. Am J Ophthalmol 1977; 83: 892 .

6 Greiner JV, Covington HI, Allansmith MR. Surface morphology of giant papillary conjunctivitis in contact lens wearers. $A m$ J Ophthalmol 1978; 85: 242-52.

7 Greiner JV, Covington HI, Korb DR. Allansmith MR. Conjunctiva in asymptomatic contact lens wearers. Am J Ophthalmol 1978; 86: 403-13.

8 Kessing SV. Mucus gland system of the conjunctiva. Acta Ophthalmol (Kbh) 1968; suppl 95.

9 Lemp MA, Holly FJ, Iwata S, Dohlman CH. The precorneal tear film. Arch Ophthalmol 1970; 83: 89-94.

10 De Haas EBH. Dessication of cornea and conjunctiva after sensory denervation. Arch Ophthalmol 1962; 67: 79.

11 Wright $P$, Mackie IA. Mucus in the healthy and diseased eye Trans Ophthalmol Soc UK 1977; $97: 1-7$.

12 Williamson J, Brown RL. The Eye in Connective Tissue Diseases. London: Edward Arnold, 1978.

13 Mackie IA. Role of corneal nerves in destructive disease of the cornea. Trans Ophthalmol Soc UK 1978; 98: 343-7.

14 Greiner JV, Kenyon KR, Henriquez AS, Korb DR, Weidman TA, Allansmith MR. Mucus secretory vesicles in conjunctival epithelial cells of wearers of contact lenses. Arch Ophthalmol 1980; 98: 1843-6.

15 Thiéry J-P. Mise en évidence des polysaccharides sur coupes fines en microscopie électronique. J Microscopie 1967; 6: 987-1018.

16 Tagawa S. Ueber die Beschaffenheit der Hornhautoberflache nach Trigeminus durch schneidung. Arch Augenheilkd 1930; 102: 231.

17 Whitlock RT, Wheeler HO. Coupled transport of solute and water across rabbit gallbladder epithelium. J Clin Invest 1964; 43: 2249-65.

18 Tormey J McD. Diamond JM. The ultrastructural route of fluid transport in rabbit gall bladder. J Gen Physiol 1967; 50: 2031-61.

19 Curran PF, MacIntosh JR. Model system for biological water transport. Nature 1962; 193: 347.

20 Diamond JM. Transport of salt and water in rabbit and guinea-pig gallbladder. J Gen Physiol 1964; 48: 1-14.

21 Diamond JM, Bossert WH. Standing-gradient osmotic flow. A mechanism for coupling of water and solute transport in epithelia. J Gen Physiol 1967; 50: 2061-83.

22 Fredericksen $\mathrm{O}$. Rostgaard J. Absence of dilated lateral intercellular spaces in fluid-transporting frog gallbladder epithelium. Direct microscopy observations. J Cell Biol 1974; 61: 830-4.

23 Rostgaard J, Fredericksen O. Fluid transport and dimensions of epithelial cells and intercellular spaces in frog gallbladder. Cell Tissue Res 1981; 215: 223-47. 